Original article (short paper)

\title{
Patellofemoral pain and sports practice: reduced symptoms and higher quality of life in adolescent athletes as compared to non-athletes
}

\author{
Danilo de Oliveira Silva \\ Maira Bergamaschi Coura \\ Marina Waiteman \\ Juliana Pradela \\ Marcella Ferraz Pazzinatto \\ Universidade Estadual Paulista "Júlio de Mesquita Filho", Presidente Prudente, SP, Brasil \\ Fernando Henrique Magalhães \\ Universidade de São Paulo, São Paulo, SP, Brasil \\ Fábio Mícolis de Azevedo \\ Universidade Estadual Paulista "Júlio de Mesquita Filho", Presidente Prudente, SP, Brasil
}

\begin{abstract}
Patellofemoral pain (PFP) is common in athletes and physically active individuals and it is one of the most frequent knee disorders among adolescents. However, the impact of the severity of PFP symptoms on quality of life (QOL) has been barely investigated. Thus, we aimed to compare the level of PFP and the self-reported QOL between adolescent athletes and non-athletes, and to explore the relationship between the severity of PFP symptoms and QOL. Fifty-six adolescents with PFP (22 athletes and 34 non-athletes) were asked to fulfill the Anterior Knee Pain Scale (AKPS) and the QOL dimension of the Knee Outcome in Osteoarthritis Survey (KOOS). Between groups comparisons indicated that adolescent non-athletes presented higher severity of PFP symptoms and lower QOF as compared with adolescent athletes. Significant correlations between the severity of PFP and QOL were found for both groups, regardless of the athletic status.
\end{abstract}

Keyword: adolescent; quality of life; knee; physical activity; athletic performance.

\section{Introduction}

Patellofemoral pain (PFP) is often observed in athletes and subjects physically active and it is one of the most common knee disorders among adolescents (Molgaard, Rathleff, \& Simonsen, 2011; Rathleff, Roos, Olesen, Rasmussen, $\&$ Arendt-Nielsen, 2013). Population-based studies have indicated that the prevalence of PFP among adolescents aged 15-19 years old is 7\%, while long-standing knee pain is frequently reported by this population with average pain duration of more than three years (Molgaard et al., 2011; Rathleff, et al., 2013). Thus, it seems that PFP may be present among even younger $(<15$ years old) adolescents. Besides long-standing pain, adolescents with PFP usually report important reductions in function and health-related quality of life (QOL) as compared to asymptomatic adolescents (Rathleff, et al., 2013).

PFP has also been associated with increased levels of physical activity practice (Fairbank, Pynsent, Vanpoortvliet, \& Phillips, 1984). For instance, higher levels of knee pain were reported by those who participated in pain-exacerbating activities during the preceding days (Thomeé, Augustsson,
Karlsson, \& Thomee, 1999). In this direction, athletes with PFP may be more exposed to symptoms aggravation and consequently have greater reduction in the QOL as compared to non-athletes. Injuries in athletes result in high health care costs and impose a significant physiological and psychosocial health impact (McLeod, Bay, Parsons, Sauers, \& Snyder, 2009). Psychosocial examination is an important component of a sports injury appraisal because reduced QOL due to knee pain may demotivate the participation in professional sports activities (Cheung, Zhang, \& Ngai, 2013). Despite these facts, the impact of QOL in association with sport-related injury remains an issue that has been barely investigated in the field of sports medicine.

The progression of PFP to more severe orthopedic disorders such as knee osteoarthritis and anterior cruciate ligament injury has been a matter of debate (Crossley, 2014; Myer et al., 2014). Therefore, early identification of risk factors related to PFP may be critical for the prevention of PFP in young and highly active athletes. To the best of our knowledge, this is the first study that explores the association between the severity of PFP and QOL in adolescent athletes and non-athletes with PFP. Such information has the potential to provide insights in order 
to formulate adequate rehabilitation strategies for adolescent with PFP considering psychosocial approaches.

Therefore, the aims of this study were (1) to compare the level of PFP symptoms and the self-reported QOL between adolescent athletes and non-athletes with PFP, and (2) to explore the relationship between the level of PFP symptoms and QOL in adolescent athletes and non-athletes with PFP. In view of the literature briefly reviewed above, we hypothesized that adolescent athletes would report a greater level of PFP and reduced QOL as compared to non-athletes. In addition, we expected the severity of PFP symptoms to be associated with decreased QOL in both groups.

\section{Methods}

This was a cross-sectional study that compared adolescent athletes aged between 12 to 18 years old diagnosed with PFP with a control group of non-athletes with PFP. The study was approved by the Sao Paulo State University Human Ethics Committee (number: 037518/2015). Before completing the survey, the participants' parent or guardian signed an informed consent form with the participant's agreement.

\section{Participants}

Fifty-six adolescents were recruited and allocated in two groups. The group of adolescent athletes $(\mathrm{N}=22 ; 14$ Males and 8 Females) were recruited via athletic trainer and coach contacts at a sport center complex. The athletes were regularly involved in training and competition activities of the following modalities: basketball, volleyball, handball and soccer (Table 1). Adolescent non-athletes ( $\mathrm{N}=34 ; 23$ Males and 11 Females) were recruited from 4 local high schools. In order to obtain this sample, we screened 80 adolescent athletes (total population of adolescent athletes available at the sport center complex of the city) and 180 adolescent non-athletes (the maximum number of adolescents that was possible to assess). Therefore, the rate of adolescent athletes and non-athletes with PFP corresponded to $27.5 \%$ and $18.8 \%$, respectively. Thus, the presented study included a higher number of adolescent non-athletes as compared with athletes (due to the higher number of non-athletes that could be screened initially). Anthropometric data of the two groups can be found in Table 2. Participants were recruited between June and November 2015. In order to achieve homogeneity of the sample, only participants involved in recreational physical activity were included in the group of non-athletes. To be classified as physically active, the participants had to be fulfill the International Physical Activity Questionnaire (IPAQ) Scoring Protocol short form. The two criteria used for classification as physically active were: a) vigorous activity at least 3 days per week, or b) moderate activity at least 5 days per week (IPAQ Research Committee, 2005).
Table 1. Sports modality practiced by the adolescents with patellofemoral pain of athletes group.

\begin{tabular}{lccc}
\hline Sport & Male & Female & Total \\
\hline Basketball & $8(57.14 \%)$ & $3(37.50 \%)$ & $11(50.00 \%)$ \\
Handball & $3(21.42 \%)$ & $1(12.50 \%)$ & $4(18.18 \%)$ \\
Soccer & $3(21.42 \%)$ & - & $3(13.63 \%)$ \\
Volleyball & - & $4(50.00 \%)$ & $4(18.8 \%)$ \\
Total & $14(100 \%)$ & $8(100 \%)$ & $22(100 \%)$ \\
\hline
\end{tabular}

The number of participants in each modality of sport and the respective percentage $(\%)$.

Table 2. Summary of subject demographics.

\begin{tabular}{lccc}
\hline & $\begin{array}{c}\text { Adolescent } \\
\text { Athletes }\end{array}$ & $\begin{array}{c}\text { Adolescents } \\
\text { Non-athletes }\end{array}$ & \\
\hline Data & Mean $\pm \mathrm{SD}$ & Mean $\pm \mathrm{SD}$ & p-value \\
\hline Age (years) & $14.45 \pm 1.29$ & $13.85 \pm 1.18$ & 0.168 \\
Body Mass (kg) & $68.11 \pm 12.52$ & $66.88 \pm 13.45$ & 0.356 \\
Height (m) & $1.77 \pm 0.10$ & $1.73 \pm 0.08$ & 0.095 \\
Previous month & $4.31 \pm 1.35$ & $5.23 \pm 1.77$ & $0.044^{*}$ \\
pain (VAS) & & & \\
Symptoms dura- & $19.45 \pm 12.51$ & $22.03 \pm 17.06$ & 0.545 \\
tion (Months) & & & \\
AKPS score & $84.73 \pm 10.85$ & $77.47 \pm 10.17$ & $0.017^{*}$ \\
KOOS-QOL score & $77.84 \pm 18.77$ & $67.87 \pm 17.36$ & $0.047^{*}$ \\
Gender & 15 males/ 7 & 23 males/ 11 & - \\
& females & females & \\
\hline
\end{tabular}

Abbreviation: Mean $\pm \mathrm{SD}=$ Mean and Standard Deviation; VAS $=$ Visual Analogue Scale; AKPS = Anterior Knee Pain Scale; KOOS-QOL = Knee Outcome in Osteoarthritis Survey, Quality of Life dimension. The percentage of females in the Adolescent Athletes group is $46.66 \%$ and in the Adolescent Non-Athletes group is $47.82 \%$

*Statistically significant difference between groups.

Adolescents of both groups were diagnosed with PFP if they met the following criteria (Rathleff, et al., 2013): insidious onset of anterior knee or retropatellar pain for at least the past 6 weeks; pain provoked by at least 2 of the following activities: prolonged sitting or kneeling, squatting, running, or stair walking; tenderness on palpation of the posterior surface of the patella; and worst pain intensity in the previous month of at least $3 \mathrm{~cm}$ on a $10 \mathrm{~cm}$ visual analog scale. Exclusion criteria were concomitant injury or pain from the hip, lumbar spine, or other knee structures; previous knee surgery; patellofemoral instability; knee joint effusion; use of physiotherapy for treating knee pain within the previous year; currently undergoing medical treatment; or daily or weekly use of anti-inflammatory drugs. Participants of the group of non-athletes were excluded if involved in sports competition.

\section{Procedure}

All included participants completed two self-administered questionnaires: Anterior Knee Pain Scale (AKPS) and Knee Outcome in Osteoarthritis Survey (KOOS). The surveys were administered in a classroom (non-athletes group) or at the sport 
center complex (athletes group) and took approximately 30 minutes to be completed. The participants were assisted by a trained physical therapist.

\section{Instruments}

The AKPS is a 13-item questionnaire that evaluates subjective symptoms and functional limitations associated with PFP and can be used to assess the severity of PFP (Cheung et al., 2013). The questionnaire score ranges from 0 to 100 , with the maximum total score of 100 indicating no disability and 0 indicating the worst symptoms and restrictions of daily life functions. This tool has been validated for subjects with PFP and has been reported to demonstrate high test-retest reliability (Crossley, Bennell, Cowan, \& Green, 2004).

The KOOS was constructed on the basis of the literature review and expert panel (Roos, Roos, Lohmander, Ekdahl, \& Beynnon, 1998). The KOOS is a 42-item questionnaire that covers five dimensions reported separately: pain, symptoms, activities of daily living, sport and recreation function, and knee-related quality of life. This tool has been validated and also demonstrates high test-retest reliability (Singh, Luo, Landon, \& Suarez-Almazor, 2014). Each dimension has its own score ranging from 0 to 100 . The dimension of interest in this study was the knee-related QOL, with higher scores indicating better QOL and lower scores indicating worse QOL.

\section{Statistical Analysis}

Statistical analyses were performed using the Statistical Package for Social Sciences (SPSS) version 18.0 (SPSS Inc., Chicago IL). Descriptive statistics for sample characteristics were expressed using mean (standard deviation). To determine the normality and homogeneity of the data, Shapiro-Wilk's and Levene's tests were used, respectively (Field, 2013). The severity of PFP and QOL were compared between groups using independent-samples t test. A Pearson product-moment correlation matrix was used to examine the relationships between severity of PFP and QOL in each group.

\section{Results}

The data were found to be normally distributed for all variables. In addition, equal variances were assumed in the Levene's test for all variables (F-value $<1.22$; $p$-value $>0.274$ ). Therefore, parametric tests could be used for comparisons, despite the higher number of participants in the group of adolescent non-athletes (Field, 2013). There were no significant differences between the groups for body mass, age or height (Table 2). The adolescent athletes with PFP scored higher in the AKPS as compared with the adolescent non-athletes ( $p=$ 0.017) with PFP. Additionally, the athletes with PFP scored higher in the QOL dimension of the KOOS as compared with the non-athletes $(p=0.044)$.
Our findings indicated a significant positive relationship between the severity of PFP and the QOL in both groups, that is, the worse the symptoms of PFP the worse the QOL of adolescents with PFP, regardless of their athletic status (Table 3).

Table 3. Correlations between level of patellofemoral pain and quality of life (one of the five dimensions of KOOS) in adolescent athletes and non-athletes.

\begin{tabular}{lcc}
\hline $\begin{array}{c}\text { Anterior Knee Pain } \\
\text { Scale }\end{array}$ & KOOS-QOL & p-value \\
\hline Athlete & $\mathrm{r}=0.671^{*}$ & $<0.001$ \\
Non-athlete & $\mathrm{r}=0.781^{*}$ & $<0.001$ \\
\hline
\end{tabular}

Abbreviation: KOOS-QOL $=$ Knee Outcome in Osteoarthritis Survey - Quality of Life dimension; $r=$ Pearson product-moment correlation matrix value.

*Statistically significant correlation.

\section{Discussion}

As previously mentioned, PFP is one of the most common diagnoses in sports medicine, accounting for nearly $25 \%$ of all identified knee injuries (De Oliveira Silva, Briani, Pazzinatto, Ferrari, Aragão, Albuquerque, et al., 2015a; Pazzinatto et al., 2015; Silva et al., 2015). It is a common problem, encompassing a variety of symptoms without a single identifiable cause (De Oliveira Silva, Briani, Pazzinatto, Ferrari, Aragão, \& de Azevedo, 2015b; Witvrouw et al., 2014). Multiple intrinsic anatomic factors are combined with extrinsic environmental factors thereby leading to a knee pain disorder that can be difficult for clinicians and researchers to comprehend (Briani et al., 2015; Herbst et al., 2015). Despite the importance and high-incidence of PFP, there are some lacks in the currently established literature, which our study aimed to examine. For instance, previous studies in this field have focused on females with PFP aged 18-35 years old (Boling et al., 2010; De Oliveira Silva et al., 2015a; Silva et al., 2015), while few studies have investigated the male population. Therefore, a notably strengthening of our study was the inclusion of males and females adolescent athletes and non-athletes with PFP. The impact of PFP on QOL is another point that has been barely investigated and hence our findings extend the current knowledge.

We hypothesized that: 1) adolescent athletes would report a greater level of PFP symptoms and reduced QOL as compared to non-athletes and 2) the level of PFP would be positively associated with QOL in both groups. Contrastingly, our findings indicated that adolescent athletes reported lower severity of PFP symptoms and greater QOL as compared to non-athletes. On the other hand, our second hypothesis was confirmed as the level of PFP was positively associated with QOL in both groups. Our results indicate that the severity of PFP is strongly correlated with an important component of health status as QOL. These findings reinforce the necessity of including patient's self-reported measures to assess the effects of PFP across a broad spectrum of health status, so as to provide a more global and complete assessment of these individuals.

A large amount of biomechanical and physiological alterations have been observed in individuals with PFP. 
For instance, many retrospective studies have shown that adults with PFP present hip muscle weakness as compared to controls (Cant, Pineux, \& Pitance, 2014; Fredericson \& Yoon, 2006; Razeghi, Etemadi, Taghizadeh, \& Ghaem, 2010). However, these studies did not determine whether alterations such as muscle weakness are causes or effects of PFP. In a recent prospective study, Herbst et al. (2015) showed that, before developing PFP, adolescents actually demonstrated greater hip strength than those who remained healthy. The authors speculated that the adolescents with PFP probably developed greater hip abductor strength to compensate for an increased hip adduction patterns, which is an alteration that have been widely reported in individuals with PFP during functional activities (Barton, Levinger, Menz, \& Webster, 2009; Lankhorst, Bierma-Zeinstra, \& van Middelkoop, 2013; Nakagawa, Moriya, Maciel, \& Serrão, 2012). As long as the greater hip abduction strength was able to correct the increased hip adduction kinematics, the participants remained asymptomatic. When this compensatory behavior failed, the participants developed PFP. Therefore, it is reasonable to speculate that similar mechanisms may have played a role in the present study, which may explain, at least in part, the rejection of our first hypothesis. That is, the adolescent athletes with PFP may have developed compensatory behaviors for longer periods due to the high-intensity training and well-prepared musculoskeletal system, thereby attenuating the severity of PFP symptoms and its impact on QOL. However, future prospective studies are needed in order to better explore this conjecture.

A matter of frequent investigation in PFP is the impact of biomechanical alterations on physical function and the severity of PFP ( De Oliveira Silva, Briani, Pazzinatto, Ferrari, Aragão, $\&$ de Azevedo, 2015c). However, the relationship between the severity of PFP symptoms and its corresponding impact on the QOL has been neglected. We have found a significant relationship between the level of PFP and QOL for both groups (athletes and non-athletes), with increased PFP symptoms associated with decreased QOL. The present results provide evidence that PFP severity leads to negative health-related consequences that may affect areas of the adolescent's life other than their athletic and physical activities. Similar to our results (Cheung et al., 2013) showed a significant association between the level of PFP and QOL in 19 adult professional athletes representative of the national track and field team of China. Thus, it seems that the relationship between QOL and PFP may be persistent over time, thereby leading to long-lasting impairments in the health status of physically-active subjects with PFP.

Poorly managed musculoskeletal injuries during adolescence may lead to some significant and disabling long-term health problems such as knee osteoarthritis (Crossley, 2014; McLeod et al., 2009). Utting, Davies, \& Newman, 2005 demonstrated that a substantial number of patients with patellofemoral arthritis had suffered with PFP during their adolescence. Moreover, many of these patients reported symptoms of PFP 20 years prior to their arthroplasty surgery, thereby suggesting that the problem had been continuous throughout their life and that PFP developed during adolescence might have contributed to the later establishment of patellofemoral osteoarthritis (Utting et al., 2005). Therefore, considering the relationships found in our study, it seems imperative to develop treatment strategies to recover physical function and health status in adolescents with PFP as soon as possible, regardless if they are athletes or not.

\section{Conclusion}

In summary, adolescent non-athletes presented greater level of PFP and lower QOL as compared with adolescent athletes, suggesting that the involvement in sports training and competition by adolescent athletes with PFP did not contribute to the aggravation of PFP and decrease in QOL. Furthermore, the severity of PFP symptoms was significantly associated with reduced QOL in both groups of adolescents with PFP, regardless of their athletic status, providing evidence that PFP might lead to negative consequences to adolescent's psychosocial health.

\section{References}

Barton, C. J., Levinger, P., Menz, H. B., \& Webster, K. E. (2009). Kinematic gait characteristics associated with patellofemoral pain syndrome: a systematic review. Gait \& Posture, 30(4), 405-16. doi:10.1016/j.gaitpost.2009.07.109

Boling, M., Padua, D., Marshall, S., Guskiewicz, K., Pyne, S., \& Beutler, A. (2010). Gender differences in the incidence and prevalence of patellofemoral pain syndrome. Scandinavian Journal of Medicine \& Science in Sports, 20(5), 725-730. doi:10.1111/j.160 0-0838.2009.00996.x.Gender

Briani, R. V., De Oliveira Silva, D., Pazzinatto, M. F., De Albuquerque, C. E., Ferrari, D., Aragão, F. A., \& De Azevedo, F. M. (2015). Comparison of frequency and time domain electromyography parameters in women with patellofemoral pain. Clinical Biomechanics, 30(3), 302-307. doi:10.1016/j.clinbiomech.2014.12.014

Cant, J. Van, Pineux, C., \& Pitance, L. (2014). Hip muscle strength and endurance in femeles with patellofemoral pain: a systematic review with meta-analysis. The International Journal of Sports Physical Therapy, 9(5), 564-582.

Cheung, R. T. H., Zhang, Z., \& Ngai, S. P. C. (2013). Different relationships between the level of patellofemoral pain and quality of life in professional and amateur athletes. $P M \& R, 5(7), 568-572$. doi:10.1016/j.pmrj.2012.12.007

Crossley, K. (2014). Is patellofemoral osteoarthritis a common sequela of patellofemoral pain? British Journal of Sports Medicine, 48, 409-410. doi:10.1136/bjsports-2014-093445

Crossley, K. M., Bennell, K. L., Cowan, S. M., \& Green, S. (2004). Analysis of outcome measures for persons with patellofemoral pain: which are reliable and valid? Archives of Physical Medicine and Rehabilitation, 85(5), 815-822. doi:10.1016/S0003-9993(03)00613-0

De Oliveira Silva, D., Briani, R., Pazzinatto, M., Ferrari, D., Aragão, F., \& Azevedo, F. (2015)c. Vertical ground reaction forces are associated with pain and self-reported functional status in recreational athletes with patellofemoral pain. Journal 
of Applied Biomechanics, 31(6), 409 - 414. doi:10.1123/ jab.2015-0048

De Oliveira Silva, D., Briani, R. V., Pazzinatto, M. F., Ferrari, D., Aragão, F. A., Albuquerque, C. E., ... Azevedo, F. M. (2015)a. Reliability and differentiation capability of dynamic and static kinematic measurements of rearfoot eversion in patellofemoral pain. Clinical Biomechanics, 30(2), 144-148. doi:10.1016/j.clinbiomech.2014.12.009

De Oliveira Silva, D., Briani, R. V., Pazzinatto, M. F., Ferrari, D., Aragão, F. A., \& de Azevedo, F. M. (2015)b. Reduced knee flexion is a possible cause of increased loading rates in individuals with patellofemoral pain. Clinical Biomechanics, 30(9), 971-975. doi:10.1016/j.clinbiomech.2015.06.021

Fairbank, J. C. T., Pynsent, P. B., Vanpoortvliet, J. a, \& Phillips, H. (1984). Mechanical Factors in the Incidence of Knee Pain in Adolescents and Young-Adults. Journal of Bone and Joint SurgeryBritish Volume, 66(5), 685-693.

Field, A. (2013). Discovering statistics using IBM SPSS statistics. (4th ed.). London.

Fredericson, M., \& Yoon, K. (2006). Physical examination and patellofemoral pain syndrome. American Journal of Physical Medicine \& Rehabilitation / Association of Academic Physiatrists, 85(3), 234-43. doi:10.1097/01.phm.0000200390.67408.f0

Herbst, K. a., Barber Foss, K. D., Fader, L., Hewett, T. E., Witvrouw, E., Stanfield, D., \& Myer, G. D. (2015). Hip Strength Is Greater in Athletes Who Subsequently Develop Patellofemoral Pain. The American Journal of Sports Medicine, 43(11), 2747-2752. doi:10.1177/0363546515599628

IPAQ Research Committee. Guidelines for data processing and analysis of the International Physical Activity Questionnaire(IPAQ), Short Form. (2005).

Lankhorst, N. E., Bierma-Zeinstra, S. M. a, \& van Middelkoop, M. (2013). Factors associated with patellofemoral pain syndrome: a systematic review. British Journal of Sports Medicine, 47(4), 193-206. doi:10.1136/bjsports-2011-090369

McLeod, T. C. V., Bay, R. C., Parsons, J. T., Sauers, E. L., \& Snyder, A. R. (2009). Recent injury and health-related quality of life in adolescent athletes. Journal of Athletic Training, 44(6), 603-610. doi:10.4085/1062-6050-44.6.603

Molgaard, C., Rathleff, M. S., \& Simonsen, O. (2011). Patellofemoral pain syndrome and its association with hip, ankle, and foot function in 16- to 18-year-old high school students: a single-blind case-control study. Journal of the American Podiatric Medical Association, 101(3), 215-222. doi:101/3/215 [pii]

Myer, G. D., Ford, K. R., Di Stasi, S. L., Barber Foss, K. D., Micheli, L. J., \& Hewett, T. E. (2014). High knee abduction moments are common risk factors for patellofemoral pain (PFP) and anterior cruciate ligament (ACL) injury in girls: Is PFP itself a predictor for subsequent ACL injury? British Journal of Sports Medicine, 0, 1-7. doi:10.1136/bjsports-2013-092536

Nakagawa, T. H., Moriya, É. T. U., Maciel, C. D., \& Serrão, A. F. V. (2012). Frontal plane biomechanics in males and females with and without patellofemoral pain. Medicine and Science in Sports and Exercise, 44(9), 1747-55. doi:10.1249/MSS.0b013e318256903a

Pazzinatto, M. F., Silva, D. O., Briani, R. V., Ferrari, D., Aragão, F. A., Albuquerque, C. E., \& Azevedo, F. M. (2015). Reliability of electromyography parameters during stair deambulation in patellofemoral pain syndrome. Motriz: Revista de Educação Física, 21(2), 207-213.

Rathleff, M. S., Roos, E. M., Olesen, J. L., Rasmussen, S., \& ArendtNielsen, L. (2013). Lower mechanical pressure pain thresholds in female adolescents with patellofemoral pain syndrome. The Journal of Orthopaedic and Sports Physical Therapy, 43(6), 414-21. doi:10.2519/jospt.2013.4383

Razeghi, M., Etemadi, Y., Taghizadeh, S., \& Ghaem, H. (2010). Could hip and knee muscle strengthening alter the pain intensity in patellofemoral pain syndrome? Iranian Red Crescent Medical Journal, 12(2), 104-110.

Roos, E. M., Roos, H. P., Lohmander, L. S., Ekdahl, C., \& Beynnon, B. D. (1998). Knee Injury and Osteoarthritis Outcome Score (KOOS)--development of a self-administered outcome measure. The Journal of Orthopaedic and Sports Physical Therapy, 28(2), 88-96. doi:10.2519/jospt.1998.28.2.88

Silva, D. O., Briani, R. V., Ferrari, D., Pazzinatto, M. F., Aragão, F. A., \& Azevedo, F. M. (2015). Ângulo Q e pronação subtalar não são bons preditores de dor e função em indivíduos com síndrome da dor femoropatelar. Fisioterapia E Pesquisa, 22(2), 169-175. doi:10.590/1809-2950/14031522022015

Singh, J. A., Luo, R., Landon, G. C., \& Suarez-Almazor, M. (2014). Reliability and clinically important improvement thresholds for osteoarthritis pain and function scales: A multicenter study. Journal of Rheumatology, 41(3), 509-515. doi:10.3899/jrheum.130609

Thomeé, R., Augustsson, J., Karlsson, J., \& Thomee, R. (1999). Patellofemoral pain syndrome: a review of current issues. Sports Medicine, 28(4), 245-262.

Utting, M. R., Davies, G., \& Newman, J. H. (2005). Is anterior knee pain a predisposing factor to patellofemoral osteoarthritis? The Knee, 12(5), 362-5. doi:10.1016/j.knee.2004.12.006

Witvrouw, E., Callaghan, M. J., Stefanik, J. J., Noehren, B., Bazett-Jones, D. M., Willson, J. D., ... Crossley, K. M. (2014). Patellofemoral pain: consensus statement from the 3rd International Patellofemoral Pain Research Retreat held in Vancouver, September 2013. British Journal of Sports Medicine, 48(6), 411-4. doi:10.1136/bjsports-2014-093450

\section{Authors' note}

Danilo de Oliveira Silva, Maira Bergamaschi Coura, Marina Waiteman, Juliana Pradela, Marcella Ferraz Pazzinatto, Fábio Mícolis de Azevedo are affiliated with the University of São Paulo State, School of Science and Technology, Physical Therapy Department, Presidente Prudente, Brazil.

Fernando Henrique Magalhães is affiliated with the School of Arts, Sciences, and Humanities, University of Sao Paulo, Sao Paulo, Brazil

\section{Acknowledgment}

To São Paulo Research Foundation (FAPESP) for a scholarship (2015/15575-4). The financial sponsors played no role in the design, execution, analysis and interpretation of data, or writing of the study. 


\section{Corresponding author}

Fernando Henrique Magalhães

Avenida Arlindo Bettio, 1000, School of Arts, Sciences and Humanities (EACH-USP), São Paulo, SP, 03828-000, Brazil.

Email: fhmagalhaes@usp.br

Manuscript received on November 11, 2015

Manuscript accepted on November 25, 2015

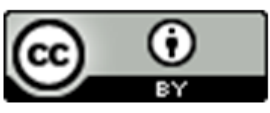

Motriz. The Journal of Physical Education. UNESP. Rio Claro, SP, Brazil - eISSN: 1980-6574 - under a license Creative Commons - Version 3.0 